\title{
Entre razões e emoções da evasão universitária, o contexto importa? Uma análise das instituições comunitárias catarinenses
}

\author{
Among reasons and emotions of university dropout, does context matter? An \\ analysis of Santa Catarina community institutions \\ Entre las razones y las emociones del abandono universitario, ¿importa el \\ contexto? Un análisis de las instituciones comunitarias de Santa Catarina
}

\author{
Cinara Gambirage ${ }^{1}$ \\ Jaison Caetano da Silva ${ }^{2}$ \\ Nelson Hein ${ }^{1}$ \\ Maria José Carvalho de Souza Domingues ${ }^{1}$ \\ Adriana Kroenke ${ }^{1}$
}

Recebido em: 07/01/2020; revisado e aprovado em: 04/10/2020; aceito em: 28/12/2020

DOI: http://dx.doi.org/10.20435/inter.v22i3.2881

\begin{abstract}
Resumo: Embora esforços crescentes tenham sido despendidos na análise do entendimento do fenômeno evasão no ensino superior, a literatura ainda é limitada e silenciosa acerca dos fatores exógenos e relacionados às características das Instituições de Ensino Superior (IES). Este estudo tem o objetivo de identificar e discutir a evasão acadêmica dos cursos de Administração e Ciências Contábeis nas IES de Santa Catarina. Visando contribuir para o entendimento da temática, adotou-se, neste estudo, uma abordagem quantitativa. Utilizaram-se como amostra os cursos de Administração e Ciências Contábeis nas IES de Santa Catarina, e o método CRiteria Importance Through Intercriteria Correlation (CRITIC) para a análise e ranqueamento das instituições quanto à evasão acadêmica de 2010 a 2014, sendo o primeiro estudo da temática que considera e evidencia a factibilidade da adoção do método. Os achados mostram que IES privadas localizadas em regiões com menor Índice de Desenvolvimento Humano (IDH) e baixa renda per capita possuem maior taxa de evasão se comparadas às IES públicas e privadas localizadas em regiões mais desenvolvidas. Na perspectiva teórica, o artigo contribui para estender o debate e o conhecimento da área ao adotar uma abordagem e metodologia quantitativa original, bem como por considerar os fatores exógenos e relacionados às características das IES. Empiricamente, o estudo fornece também suporte para gestores governamentais e educacionais avaliarem as estratégias adotadas e a eficiência dos recursos empregados nas IES.
\end{abstract}

Palavras-chave: evasão; ensino superior; Administração; Ciências Contábeis.

Abstract: Although increasing efforts have been expended in analyzing the understanding of the phenomenon of dropout in higher education, the literature is still limited and silent about exogenous factors and related to the characteristics of higher education institutions ( $\mathrm{HEI}$ ). This study aims to identify and discuss the academic dropout in Business Administration and Accounting courses in HEI of Santa Catarina. To contribute to the understanding of the theme, this study adopted a quantitative approach. We used as a sample the courses in Administration and Accounting in the Santa Catarina HEI and the CRiteria Importance Through Intercriteria Correlation (CRITIC) method for the analysis and ranking of institutions in terms of academic dropout from 2010 to 2014, being the first study of the theme that considers and evidences the feasibility adoption of the method. The findings show that private HEl located in regions with lower Human Development Index (HDI) and low per capita income have higher dropout rates compared to public and private HEI located in more developed regions. From the theoretical perspective, the article contributes to extend the debate and knowledge of the area by adopting an original quantitative approach and methodology, as well as by considering the exogenous factors related to the characteristics of the HEl. Empirically, the study also provides support for government and educational managers to evaluate the strategies adopted and the resource efficiency employed in the HEl..

Keywords: dropout; higher education; Administration; Accounting.

Resumen: Si bien se han realizado esfuerzos cada vez mayores para analizar la comprensión del fenómeno de la deserción escolar en la educación superior, la literatura aún es limitada y silenciosa sobre los factores

\footnotetext{
${ }^{1}$ Universidade Regional de Blumenau (FURB), Blumenau, Santa Catarina, Brasil.

${ }^{2}$ Universidade do Vale do Itajaí (UNIVALI), Itajaí, Santa Catarina, Brasil.
} 
exógenos y está relacionada con las características de las instituciones de educación superior (IES). Este estudio tiene el objetivo de identificar y discutir la evasión académica de los cursos de Ciencias de la Administración y Contabilidad en las Instituciones de Educación Superior de Santa Catarina. Para contribuir a la comprensión del tema, este estudio adoptó un enfoque cuantitativo. Utilizamos como muestra los cursos de Administración de Empresas y Contabilidad en las IES de Santa Catarina y el método CRiteria Importance Through Intercriteria Correlation (CRITIC) para el análisis y clasificación de instituciones en términos de deserción académica de 2010 a 2014, siendo el primer estudio del tema que considera y evidencia la viabilidad de adopción del método. Los resultados muestran que las IES privadas ubicadas en regiones con un Índice de Desarrollo Humano (IDH) más bajo y un ingreso per cápita bajo tienen tasas de abandono más altas en comparación con las IES públicas y privadas ubicadas en regiones más desarrolladas. En la perspectiva teórica, el artículo contribuye a ampliar el debate y el conocimiento del área mediante la adopción de un enfoque cuantitativo y una metodología original, así como al considerar los factores exógenos relacionados con las características de las IES. Empiricamente, el estudio también brinda apoyo a los gerentes gubernamentales y educativos para evaluar las estrategias adoptadas y la eficiencia de los recursos empleados en las IES.

Palabras clave: deserción; educación superior; Administración de Empresas; Contabilidad.

\section{INTRODUÇÃO}

A prática da evasão em cursos de graduação nas Instituições de Ensino Superior, sejam elas públicas, sejam elas privadas, é uma problemática recorrente e que gera desperdícios financeiros, sociais e acadêmicos. No último Censo da Educação Superior, realizado pelo Instituto Nacional de Estudos e Pesquisas Educacionais Anísio Teixeira [INEP] (2017), apesar de o número de matrículas na rede pública em cursos de graduação ter dobrado nos últimos 10 anos (cresceu mais de 103\%), a taxa de evasão universitária continuou estável e alta (24\%). Nas Instituições de Ensino Superior (IES) públicas, a evasão representa recurso público investido sem o devido retorno, já que são alocados professores, funcionários, equipamentos e espaço físico, cujo aproveitamento é subestimado.

A evasão pode ser ainda mais preocupante para as IES privadas, pois ela representa redução de receita, uma vez que os desistentes não contribuem mais com as mensalidades, fato que pode comprometer o funcionamento dos cursos de graduação (SILVA FILHO et al., 2007; OLIVEIRA; BARBOSA, 2016). Nestas instituições, os números de desistência também são ascendentes. A taxa de evasão no ensino superior privado aumentou 4\% entre 2011 e 2016, indo de 19\% do total de estudantes para 23\% (INEP, 2017).

A literatura aponta que os motivos que levam à evasão no ensino superior são amplos e se alteram conforme o contexto, entretanto alguns fatores são comuns, tais como a identidade pessoal (aptidões motoras, por exemplo), questões ambientais (estímulos) e sociais (família, parentes e amigos), desde a sua infância, e socioeconômicos (renda, capital cultural) (LUNA et al., 2014). Em suma, há fatores semelhantes para a ocorrência desse fenômeno entre as diferentes áreas do saber, envolvendo, inclusive, países distintos (SILVA FILHO et al., 2007).

Em termos teóricos, as abordagens da temática permeiam três eixos principais: o primeiro diz respeito às questões psicológicas, o qual aborda fatores relacionados às características individuais dos estudantes, a exemplo da orientação vocacional e imaturidade do estudante; o segundo eixo aborda os fatores endógenos que compreendem questões acadêmicas como currículos desatualizados e rígidos, didática docente, insuficiência de estrutura de apoio, como laboratórios, e ausência de laços afetivos na universidade; e o terceiro eixo compreende os fatores exógenos. Este último está relacionado às condições da profissão no mercado de trabalho, conjunturas socioeconômicas, vinculadas às dificuldades financeiras dos estudantes (BRAGA; PEIXOTO; BOGUTCHI, 2003). 
Apesar da atualidade, relevância e dos esforços crescentes dos pesquisadores terem sido despendidos na análise do entendimento do fenômeno evasão no ensino superior, a literatura ainda é limitada e silenciosa sobre fatores exógenos e relacionados às características das Instituições de Ensino Superior como eixo principal dessa temática (CUNHA et al., 2015). Diante disso, este artigo busca identificar e discutir a evasão acadêmica dos cursos de Administração e Ciências Contábeis nas Instituições de Ensino Superior de Santa Catarina. Para estender esse debate e o conhecimento da temática, o estudo adota uma abordagem e metodologia quantitativa original, bem como considera os fatores exógenos e relacionados às características das IES.

Portanto, diferentemente dos trabalhos de Baggi e Lopes (2011), Leal, Miranda e Carmo (2013), Ramos, Nez e Hein (2014), Cunha et al. (2015) e Cunha, Nascimento e Oliveira Durso (2016), este estudo discute a evasão no ensino superior por meio de uma abordagem quantitativa e, para o avanço do conhecimento da área, é o primeiro estudo que considera o método CRiteria Importance Through Intercriteria Correlation (CRITIC). Em segundo lugar, este trabalho considera o conjunto dos principais eixos que permeiam a discussão da evasão no ensino superior: questões psicológicas, fatores endógenos, exógenos e relacionados às características das IES. Em terceiro lugar, todas as categorias de IES são exploradas.

Para isso, utilizaram-se como amostra os cursos de Administração e Ciências Contábeis nas IES de Santa Catarina, e o método CRITIC para a análise e ranqueamento das instituições quanto à evasão acadêmica de 2010 a 2014, sendo o primeiro estudo da temática que considera e evidencia a factibilidade da adoção do método. As variáveis taxa de permanência, conclusão acumulada e desistência acumulada foram utilizadas para a análise da evasão e obtenção do ranqueamento das instituições com maior ou menor número de evasão acadêmica. Ao selecionar as variáveis da referida amostra, obteve-se um total de 53 instituições.

Os resultados evidenciaram que, em ambos os cursos de graduação, a taxa de desistência acumulada é a que apresenta maior variação entre as IES. O curso de Administração possui mais evasão se comparado ao de Ciências Contábeis. No ranking do curso de Administração, a Faculdade Cenecista de Joinville, Faculdade Municipal de Palhoça e Universidade Federal de Santa Catarina (UFSC) possuem menor taxa de evasão; por outro lado, a Faculdade Concórdia, Borges Mendonça e Universidade Alto Vale do Rio do Peixe (UNIARP) possuem maior taxa de evasão. No curso de Ciências Contábeis, a Universidade do Extremo Sul Catarinense, UFSC e FACVEST apresentam menor taxa de evasão; enquanto a Faculdade Empresarial de Chapecó, Sociesc e Universidade Alto Vale do Rio do Peixe (UNIARP) apresentam maior taxa de evasão.

Destaca-se ainda que as IES privadas localizadas em regiões com menor Índice de Desenvolvimento Humano (IDH) e baixa renda per capita possuem maior taxa de evasão se comparadas às IES públicas e privadas localizadas em regiões mais desenvolvidas. Tomados em conjunto, tais achados se devem às demandas de subsistência se tornarem mais relevantes do que a formação no ensino superior, haja vista que grande parte dos estudantes acadêmicos pertence às classes sociais de menor poder aquisitivo. Assim, tal situação é recorrente com estudantes pertencentes a essa classe econômica social e que possuem limitações para seu ingresso em uma IES pública (ausência da aquisição de Capital Cultural), na qual poderiam usufruir de recursos financeiros para seus estudos na graduação (GISI, 2006; WOLTER; DIEM; MESSER, 2014).

Este estudo amplia a literatura existente em três perspectivas principais: (i) teórica, por representar um passo na tentativa de integrar abordagens e metodologias quantitativas nos estudos das IES, considerando e evidenciando, de forma inédita, a factibilidade da adoção do 
modelo CRITIC, e por considerar os fatores exógenos e relacionados às características das IES; (ii) governamental, chama-se atenção para as políticas públicas de apoio às IES fundacionais do estado, visto que algumas IES com maior evasão representam essa categoria; e (iii) gerencial, uma vez que se fornecem subsídios aos gestores das IES para fazerem benchmarking com as demais IES, de forma a avaliarem as estratégias adotadas e eficiência dos recursos empregados.

O estudo está estruturado em cinco seções. A primeira é a introdução, que versa sobre a contextualização do tema, apresentação do objetivo do estudo, além da relevância da pesquisa e da intencionalidade da investigação. A segunda contempla o referencial teórico, que relata estudos sobre a evasão escolar, levantando dados de pesquisas aplicadas nos cursos de Ciências Contábeis e Administração e identificando os motivos que levam à evasão no curso superior em instituições públicas e privadas. A terceira trata das questões metodológicas utilizadas para concretização do estudo, citam-se o método CRITIC e o estudo sobre ranqueamento. A quarta trata da descrição, análise e discussão dos resultados obtidos com a aplicação da pesquisa. E, por último, são tecidas as considerações finais, identificando claramente o objetivo central da investigação e reafirmando as contribuições e os limites investigativos.

\section{EVASÃO NO ENSINO SUPERIOR}

A escolha profissional e, consequentemente, do curso universitário é um momento importante na carreira do indivíduo, já que ele se depara com várias opções de profissões e cursos universitários. Logo, tal escolha leva-o a ser cauteloso, pois se trata da decisão de sua carreira profissional (CUNHA; NASCIMENTO; OLIVEIRA DURSO, 2016) e há fatores condicionantes intrínsecos aos indivíduos, tais como a identidade pessoal, questões sociais (família, parentes e amigos), desde a sua infância (LUNA et al., 2014), e ambientais (estímulos e aptidões motoras, por exemplo).

A escolha certeira do curso universitário influencia em sua permanência no curso escolhido. Após isso, os estudantes universitários, ao ingressarem em uma Instituição de Ensino Superior, passarão pela fase do entusiasmo (vitória da aprovação no processo seletivo); decepção com o curso (decepção com o corpo docente, instituição, pensamento na reescolha de curso); reconquista (interesse em continuar, torna-se comprometido) e expectativa da formatura (expectativas quanto à atuação profissional). Neste contexto, a evasão pode ser entendida como uma interrupção permanente do ciclo de estudo do estudante, impedindo-o que conclua o curso e obtenha um diploma, como consequência do fracasso tanto por parte do estudante como da instituição (GATI; SAKA, 2001).

Além de uma abordagem da psicologia educacional, como fatores relacionados às características individuais dos estudantes (a orientação vocacional e imaturidade do estudante), a literatura educacional aponta também outros elementos causadores da evasão no ensino superior, bem como: endógenos e exógenos à instituição. Os fatores endógenos compreendem questões acadêmicas, como: currículos desatualizados, rígida cadeia de pré-requisitos para as disciplinas; falta de formação pedagógica ou desinteresse do docente, gerando reprovação sucessiva; insuficiência de estrutura de apoio, como laboratórios de ensino e de informática; e ausência de laços afetivos na universidade. Quanto aos exógenos, esses estão relacionados às condições da profissão no mercado de trabalho, conjunturas econômicas específicas, vinculados a dificuldades financeiras do estudante; ingresso na faculdade por imposição familiar, casamentos não planejados e nascimento de filhos (BRAGA; PEIXOTO; BOGUTCHI, 2003). 
Entre os estudos acerca do tema, ou seja, trabalhos teóricos desenvolvidos no campo da educação e que tratam da temática evasão no ensino superior no contexto nacional, cita-se o estudo de Baggi e Lopes (2011), em que fazem uma revisão bibliográfica sobre a evasão e a avaliação institucional no ensino superior. Os autores concluem que a relação entre evasão e avaliação tem sido pouco explorada pelos pesquisadores da área, sendo ainda mais restrita que a reflexão sobre a evasão no ensino superior.

Leal, Miranda e Carmo (2013) avaliaram a motivação dos estudantes de Ciências Contábeis de uma universidade pública, à luz da Teoria da Autodeterminação. Com isso, os autores concluíram que, ante os diversos objetivos dos estudantes em realizar um curso universitário, é preciso incentivar e explorar a motivação em ambientes acadêmicos. Tendo em vista que os fatores ambientais se relacionam com a permanência acadêmica, neste estudo, os autores ainda chamam atenção para a importância de selecionar os professores a lecionarem nos cursos, já que os estudantes apontaram a deficiência na didática dos professores e as limitações do curso como um dos principais motivos de desistência.

Em uma perspectiva financeira, o trabalho de Ramos, Nez e Hein (2014) trata da realização de um ranqueamento das IES associadas ao Sistema Associação Catarinense das Fundações Educacionais (ACAFE) a partir dos seus indicadores de desempenho econômico e financeiro. Os achados da pesquisa apontaram as instituições com melhor desempenho - 1ä: Universidade do Estado de Santa Catarina (UDESC), 2ạ: Centro Universitário para o Desenvolvimento do Alto Vale do Itajaí (UNIDAVI), 3a : Universidade do Oeste de Santa Catarina (UNOESC) -, contribuindo para (i) a necessidade de avaliação de desempenho destas organizações educacionais e verificação de sua sustentabilidade; (ii) a declaração dos resultados de saúde financeira para tomadas de decisões gerenciais, de forma a permitir continuidade no oferecimento dos serviços educacionais; e (iii) a prestação de contas dos resultados aos diversos usuários da comunidade.

Silva e Sauaia (2014), sob uma perspectiva econômica, verificaram a relação entre a evasão discente e a qualidade da educação oferecida no ensino superior privado. Como resultados, encontraram a existência de uma relação linear negativa entre qualidade ofertada e evasão. Logo, esta relação ilustra os riscos de expandir a oferta do ensino superior com qualidade por meio do aumento indiscriminado de vagas em instituições privadas.

Cunha et al. (2015) analisaram o comportamento de evasão dos estudantes matriculados nos cursos de graduação em Administração de Empresas e Ciências Contábeis em IES brasileiras entre 2001 e 2010. Ainda que não seja possível a sua generalização, os resultados do estudo indicaram que os cursos de Ciências Contábeis têm taxas menores de evasão nas universidades e nos centros universitários, enquanto os cursos de Administração de Empresas têm taxas maiores de evasão nas faculdades, escolas, institutos e centros de ensino tecnológico.

Cunha, Nascimento e Oliveira Durso (2016) buscaram evidências para identificar as razões que poderiam influenciar na evasão de estudantes do curso de Ciências Contábeis em IES públicas no seu primeiro ano de graduação. De modo geral, os estudantes não parecem estar propensos a abandonar o curso de acordo com os resultados da pesquisa, isto é, este resultado sugere que os estudantes ingressaram entusiasmados com o curso.

Além dos motivos expostos por essa literatura, a evasão acadêmica no setor educacional também tem ocorrido pelo crescimento do número de IES e de cursos no ensino superior, ou seja, é preciso considerar o acirramento da concorrência entre as organizações educacionais (GAMBIRAGE; XAVIER; SILVA; GREENE; GANDONOU, 2017b). Essas forças ambientais provocam às IES a implantação 
de estratégias que assegurem uma prestação de serviços de qualidade, atendendo às expectativas de seu público-alvo e possibilitando sua sobrevivência no mercado educacional (LAS CASAS; GUEVARA; MERIGHI, 2013; GAMBIRAGE; BOHN; HEIN; SILVA; DOMINGUES, 2017a).

A situação socioeconômica do país é outro problema que impacta na permanência do estudante universitário (TROELSEN; LAURSEN, 2014). No caso de estudantes brasileiros, cita-se o fato de suas demandas de primeira necessidade serem mais relevantes do que a formação em ensino superior, haja vista que são estudantes de um país em desenvolvimento e, sua maioria, pertencem às classes sociais menos favorecidas. Nesse caso, a empregabilidade fala mais alto que a busca por uma carreira profissional qualificada. Dessa forma, de acordo com Gisi (2006) e Wolter, Diem e Messer (2014), é possível apontar a falta de recursos financeiros do aluno como uma das causas para a interrupção de seus estudos. Isso acontece com estudantes de classe social menos favorecida e que possuem limitações para seu ingresso em uma IES pública (ausência da aquisição de capital cultural), na qual poderiam se beneficiar de recursos financeiros para seus estudos.

Salienta-se, ainda, que questões de ordem acadêmica devem ser consideradas também como um dos motivos de evasão no ensino superior. Tratam-se das expectativas geradas do aluno pelo curso e/ou instituição e que devem ser encorajadas de forma a não o desestimular em priorizar a conclusão do seu curso (BAGGI; LOPES, 2011).

Ainda que a evasão seja considerada um fenômeno de causas diversas, alguns fatores são comuns, como a relevância do papel da gestão universitária em intervir nestes problemas para reduzir sua dimensão. As possíveis intervenções remetem-se às alterações curriculares dos cursos, nas estratégias e metodologias de ensino, processo de avaliação e mecanismos de acompanhamento dos estudantes. Essas propostas devem ser tomadas com rigor nos primeiros semestres, uma vez que o rendimento escolar nesse período parece ser determinante para a evasão (OSBORNE; JONES, 2011). Neste sentido, este estudo também consiste em contribuir empiricamente com os gestores educacionais. O ranking das IES dos cursos de Administração e Ciências Contábeis que possuem os maiores números de evasão proporciona maior visibilidade aos gestores de tais instituições, para que avaliem as estratégias adotadas e a eficiência dos recursos empregados, tomando medidas decisórias de forma a reduzir tais números nesses cursos.

Assim, a evasão é motivo de preocupação social e institucional, tendo em vista que o estudante passará pela fase de "provação". A desistência dos acadêmicos reflete na perda de investimentos (do setor público ou privado), por isso, a relevância de estudos que tratam dessa temática, visto que o recurso direcionado ao aluno desistente não pode ser realocado para outro, assim como a própria sociedade perde quando a possibilidade de haver mais um profissional qualificado para o mercado de trabalho deixa de existir. $O$ agravamento à sociedade é ainda maior quando, junto às elevadas taxas de evasão, ocorrem as vagas que não são preenchidas nas IES (BAGGI; LOPES, 2011; CUNHA et al., 2015; CUNHA; NASCIMENTO; OLIVEIRA DURSO, 2016).

A técnica de ranqueamento é uma das formas de proporcionar maior visibilidade quanto ao posicionamento de uma organização educacional. Observa-se uma lacuna teórica e empírica na literatura quanto ao seu uso nos estudos, principalmente se o objeto de estudo for para os cursos de Administração e Ciências Contábeis. São reconhecidas as críticas que recaem sobre o ranqueamento, entretanto defende-se que o ranking proporciona mais efeitos positivos do que negativos, e seus resultados na perspectiva teórica fornecem uma rica perspectiva de que podem subsidiar análises na busca de explicações da evasão, bem como na perspectiva gerencial, podendo ser utilizados pelos gestores educacionais de forma a tomarem medidas de gestão. 
É justamente a partir da observação desta lacuna teórica e empírica que se propõe, por meio de um ranking, a identificação e discussão da evasão acadêmica dos cursos de Administração e Ciências Contábeis nas IES de Santa Catarina.

Nesse sentido, destaca-se a relevância da teoria da informação pelo fato de dispor de técnicas interessantes que auxiliam no processamento de informações mais fidedignas ao usuário, a fim de facilitar a sua tomada de decisão. Nesse caso, cita-se o método CRITIC e o do ranqueamento (empregados neste estudo), que possibilitam essa execução. Essa técnica será mais bem explorada na seção da metodologia, a seguir.

\section{METODOLOGIA DE PESQUISA}

A evasão de acadêmicos pode ser mensurada em uma instituição de ensino superior, em um curso, em uma área de conhecimento, em um período de oferta de cursos e em qualquer outro universo, desde que se tenha acesso aos dados e às informações condizentes e confiáveis. Em uma IES, a evasão pode ser medida ao organizar as informações disponíveis nos setores de registro e controle acadêmico. Além disso, é possível medir a evasão em uma turma ao comparar o número de ingressantes no ano de formação dessa turma e o número de concluintes do mesmo grupo de alunos (SILVA FILHO et al., 2007).

Neste estudo, trabalhou-se com o macroscópico da evasão, isto é, foram utilizados dados disponibilizados no sítio do INEP em suas sinopses do ensino superior, os quais foram organizados de forma que se mostre a evolução da evasão no ensino superior brasileiro a partir de agrupamentos e filtros delimitados, conforme exposto na Tabela 1, a seguir.

Portanto, ao escolher trabalhar apenas com o Estado de Santa Catarina, justifica-se pelo fato de se conhecer melhor as peculiaridades desta região e poder fazer inferências com os resultados encontrados do ranqueamento. Este estudo considera apenas estudantes de graduação de dois cursos, uma vez que uma área possui peculiaridades epistemológicas que devem ser consideradas no processo de ensino e aprendizagem (PIERRE et al., 2009; NJOKU; HEIJDEN; INANGA, 2010).

De forma geral, a amostra constituiu todas as categorias administrativas e organizações acadêmicas das IES, do estado de Santa Catarina, dos cursos de modalidade presencial de Administração e Ciências Contábeis, totalizando 53 instituições.

Tabela 1 - Filtros delimitados para obtenção da amostra

\begin{tabular}{l|l}
\hline Informações disponíveis na base & \multicolumn{1}{c}{ Filtros delimitados } \\
\hline Por categoria administrativa & $\begin{array}{l}\text { Todas: pública federal, estadual e municipal; privada com fins } \\
\text { lucrativos e sem fins lucrativos; especial }\end{array}$ \\
\hline Por organização acadêmica & $\begin{array}{l}\text { Todas: Universidade; Centro Universitário; Faculdade; Instituto } \\
\text { Federal de Educação Ciência e Tecnologia; Centro Federal de } \\
\text { Educação Tecnológica }\end{array}$ \\
\hline Por região geográfica & Sul \\
\hline Por estado & Santa Catarina \\
\hline Por área do conhecimento & Ciências Sociais Aplicadas \\
\hline Por cursos & Administração e Ciências Contábeis \\
\hline Por modalidade de ensino & Presencial \\
\hline
\end{tabular}

Fonte: Adaptado de Silva Filho et al. (2007). 
Para mensurar a evasão, trabalhou-se especificadamente com os valores que representavam a evasão de estudantes nas instituições da amostra, são eles: a) taxa de permanência; b) taxa de conclusão; e c) taxa de desistência, que somados geram o valor de $100 \%$. O estudo da evasão da amostra selecionada contemplou dados do período entre 2010 e 2014 . Tal horizonte temporal escolhido para análise justifica-se pela disponibilidade de dados.

A mensuração dos cursos analisados foi feita por meio da expressão matemática, dada por:

$$
\text { (1) Pontuação }=w_{1} T P+w_{2} T C-w_{3} T D
$$

Em que: $T P$ = taxa de permanência, $T C$ = taxa de conclusão e TD = taxa de desistência; todas são dadas em porcentagens. Observa-se o fato de que TD é tomada como sendo negativa, pois opera contra a flecha, ou seja, não agrega ao desempenho, mas sim o diminui. Este procedimento permite, inclusive, que a pontuação se torne negativa.

Os pesos foram obtidos por meio do método CRITIC, acrônimo de Criteria Importance Through Intercriteria Correlation, desenvolvido por Diakoulaki, Mavrotas e Papayannakis (1995), e utilizaram-se os conceitos de desvio-padrão das variáveis em uso e a correlação entre elas.

O peso de cada um dos $j$ critérios é calculado por meio da expressão de normalização $w_{j}=\frac{c_{j}}{\sum_{k=1}^{c} c_{k}} ; j=1,2,3$. O valor de cada $C_{j}$ é dado por: $C_{j}=\sigma_{j} \sum_{k=1}^{c}\left(1-r_{j k}\right)$, em que $\sigma_{j}$ é o desvio-padrão da variável $j$ e $r_{j k}$ é o coeficiente de correlação da variável $j$ com as duas demais variáveis em análise.

Pelo método CRITIC, os pesos dos critérios são afetados tanto pelas características dos critérios quanto pelo ponto de vista subjetivo do decisor. Com isso, tanto o desvio-padrão do critério quanto sua correlação entre outros critérios são incluídos no processo de ponderação. Com efeito, o ranking é formado por meio do valor do score obtido pela instituição, ou seja, quanto maior, melhor será sua posição.

\section{DESCRIÇÃO, ANÁLISE E DISCUSSÃO DOS RESULTADOS}

Para identificar o ranking das IES, a taxa de permanência, taxa de conclusão e taxa de desistência das IES foram utilizadas como forma de mensurar a evasão acadêmica dos cursos de Administração e Ciência Contábeis. Foram utilizadas as médias dessas variáveis pelo fato de uma mesma IES/curso se repetir nos dados, já que a cada ano há novos entrantes, inclusive, apresentando mais de uma turma do mesmo curso no mesmo ano/IES. De forma a melhor apresentar os resultados da análise dos dados e sua comparação, trabalhou-se com duas amostras: IES com curso de Administração e IES com curso de Ciências Contábeis.

A Tabela 2 apresenta o cálculo da CRITIC para os cursos de Administração e Ciências Contábeis. O peso de cada variável é utilizado para identificar qual delas apresentaram maior ou menor peso na informação. A interpretação do peso da informação é fundamentada na situação em que o peso máximo é alcançado em 1 , quando há informação contida nas respostas obtidas. O peso da informação aumenta na proporção em que se aproxima de 1. Portanto, quanto maior for o peso, maior é a informação transmitida, ao passo que, quanto mais próximo de zero for o peso, menor o grau de informação presente na variável. Assim, a análise consistiu na interpretação da variável que apresentou maior peso de informação. 
Tabela 2 - Peso da informação

\begin{tabular}{l|c|c|c}
\hline \multirow{2}{*}{ Curso } & \multicolumn{2}{|c}{ Variáveis } \\
\cline { 2 - 4 } & Taxa de permanência & $\begin{array}{c}\text { Taxa de conclusão } \\
\text { acumulada }\end{array}$ & $\begin{array}{c}\text { Taxa de desistência } \\
\text { acumulada }\end{array}$ \\
\hline Administração & 0,298 & 0,403 & 0,597 \\
\hline Ciências Contábeis & 0,240 & 0,346 & 0,415 \\
\hline
\end{tabular}

Fonte: Dados da pesquisa.

Para o curso de Administração, percebe-se que a variável com maior peso na informação $(59,7 \%)$ foi a taxa de desistência acumulada. Com isso, infere-se que esta variável apresentou o maior efeito surpresa, apresentando, assim, a maior quantidade de informações, ou seja, os valores das taxas de desistência acumulada de cada IES são bem variados. Nesse sentido, considera-se importante analisar esse item, visto que as IES possuem resultados bastante divergentes. Em contrapartida, a variável taxa de permanência se apresentou com menor peso na informação $(29,8 \%)$. Logo, esta variável não apresenta efeito surpresa, uma vez que as taxas de permanência das IES possuem pouca variação, levando, assim, à constatação de que transmite pouca informação.

Esses resultados são próximos na amostra das IES do curso de Ciências Contábeis, quando a variável taxa de desistência acumulada é também a que possui maior peso da informação $(41,5 \%)$, constatando um efeito surpresa; enquanto a variável taxa de permanência apresentou menor peso da informação (24\%), refletindo na transmissão de pouca informação e/ou variabilidade da informação. Em suma, o que se observa é que em ambos os cursos a variável taxa de desistência é a que possui maior peso na informação, o que significa que o número de estudantes desistentes é o que mais apresenta variação entre as IES, se comparado ao número de estudantes permanentes e concluintes. Além disso, o curso de Administração apresenta maiores variações na taxa de evasão se comparada com a do curso de Ciências Contábeis.

A literatura preconiza que dados mais dispersos são aqueles que carregam maior peso de informação; em outras palavras, são dados que precisam ser mais bem entendidos e analisados, por serem dados que apresentam resultados surpreendentes (ver BENTES; MENEZES; MENDES, 2009). É o que leva à corroboração da análise realizada nas três variáveis deste estudo. Nesse caso, enfatiza-se que as médias das taxas de desistência acumulada são as mais elevadas nas IES de ambos os cursos. Ademais, a evasão no curso de Administração é maior do que no curso de Ciências Contábeis. Esses achados sugerem que os ingressantes que optam pelo curso de Administração não estão convictos dessa escolha, o que os leva à desistência do curso. Já os ingressantes do curso de Ciências Contábeis estariam mais seguros da decisão de ingresso nesse curso, o que reflete numa redução da taxa de evasão, se comparada a do curso de Administração.

Por meio do coeficiente gerado a partir da média das taxas de permanência, conclusão e desistência acumuladas, tornou-se possível a construção do ranqueamento das IES dos cursos de Administração e Ciências Contábeis quanto à evasão acadêmica, o qual é representado pelos valores constantes em scores de pontuação (Tabela 4). 
Tabela 3 - Lista completa das IES da amostra com descrição das siglas (quando for o caso)

\begin{tabular}{|c|c|c|}
\hline N. & Sigla & Nome completo da instituição \\
\hline 1 & ANHANGUERA & Faculdade Anhanguera de Joinville \\
\hline 2 & AVANTIS & Faculdade AVANTIS \\
\hline 3 & BARDDAL & Faculdade Barddal de Ciências Contábeis \\
\hline 4 & BORGES MENDONÇA & Faculdade Borges de Mendonça \\
\hline 5 & CATÓLICA & Centro Universitário - Católica de Santa Catarina em Jaraguá do Sul \\
\hline 6 & ESTÁCIO DE SÁ & Centro Universitário Estácio de Sá de Santa Catarina \\
\hline 7 & ESUCRI & Escola Superior de Criciúma \\
\hline 8 & FACC & Faculdade Concórdia \\
\hline 9 & FACE & Faculdade Cenecista de Joinville \\
\hline 10 & FACULDADE DECISÃO & Faculdade Decisão \\
\hline 11 & FACULDADE SINERGIA & Faculdade Sinergia \\
\hline 12 & FACVEST & Centro Universitário FACVEST \\
\hline 13 & FAE & Faculdade FAE Blumenau \\
\hline 14 & FAED & Faculdade Educacional de Dois Vizinhos \\
\hline 15 & FAEM & Faculdade Empresarial de Chapecó \\
\hline 16 & FAI & Faculdade de Itapiranga \\
\hline 17 & FAMEBLU & Faculdade Metropolitana de Blumenau \\
\hline 18 & FAMEG & Faculdade Metropolitana de Guaramirim \\
\hline 19 & FAMESUL & Faculdade Metropolitana de Rio do Sul \\
\hline 20 & FAP & Faculdade Regional Palmitos \\
\hline 21 & FAPAG & Faculdade Porto das Águas \\
\hline 22 & FASC & Faculdade de Santa Catarina \\
\hline 23 & FCSF & Faculdade de Ciências Sociais de Florianópolis \\
\hline 24 & FEAN & Faculdade Energia de Administração e Negócios \\
\hline 25 & FLC & Faculdade do Litoral Catarinense \\
\hline 26 & FMPSC & Faculdade Municipal de Palhoça \\
\hline 27 & FUCAP & Faculdade Capivari \\
\hline 28 & FURB & Universidade Regional de Blumenau \\
\hline 29 & HORUS & Faculdade Pinhalzinho \\
\hline 30 & IBES & Instituto Blumenauense de Ensino Superior \\
\hline 31 & IES & Instituto de Ensino Superior da Grande Florianópolis \\
\hline 32 & IFES & Faculdade do Vale do Itajaí Mirim \\
\hline 33 & IFES & Instituto Cenecista Fayal de Ensino Superior \\
\hline 34 & INESA & Instituto de Ensino Superior Santo Antônio \\
\hline 35 & SOCIESC & Faculdade SOCIESC \\
\hline 36 & UDESC & Fundação Universidade do Estado de Santa Catarina \\
\hline 37 & UFSC & Universidade Federal de Santa Catarina \\
\hline 38 & UNC & Universidade do Contestado \\
\hline 39 & UNESC & Universidade do Extremo Sul Catarinense \\
\hline 40 & UNIARP & Universidade Alto Vale do Rio do Peixe \\
\hline 41 & UNIASSELVI & Centro Universitário Leonardo da Vinci \\
\hline 42 & UNIBAN & Faculdade União Bandeirante \\
\hline 43 & UNIBAVE & Centro Universitário Barriga Verde \\
\hline 44 & UNIDAVI & Centro Universitário para o Desenvolvimento do Alto Vale do Itajaí \\
\hline 45 & UNIFEBE & Centro Universitário de Brusque \\
\hline 46 & UNIPLAC & Universidade do Planalto Catarinense \\
\hline 47 & UNISOCIESC & Centro Universitário Tupy \\
\hline 48 & UNISUL & Universidade do Sul de Santa Catarina \\
\hline 49 & UNIVALI & Universidade do Vale do Itajaí \\
\hline 50 & UNIVILLE & Universidade da Região de Joinville \\
\hline 51 & UNOCHAPECÓ & Universidade Comunitária da Região de Chapecó \\
\hline 52 & UNOESC & Universidade do Oeste de Santa Catarina \\
\hline 53 & USJ & Centro Universitário Municipal de São José \\
\hline
\end{tabular}


Tabela 4 - Ranking das IES quanto à evasão acadêmica

\begin{tabular}{|c|c|c|c|c|c|}
\hline \multicolumn{3}{|c|}{ Curso de Administração } & \multicolumn{3}{|c|}{ Curso de Ciências Contábeis } \\
\hline Ranking & Instituição & Score & Ranking & Instituição & Score \\
\hline 1 & FACE & 24,24 & 1 & UNESC & 13,65 \\
\hline 2 & FMPSC & 17,26 & 2 & UFSC & 12,78 \\
\hline 3 & UFSC & 13,86 & 3 & FACVEST & 10,35 \\
\hline 4 & ANHANGUERA & 9,26 & 4 & ANHANGUERA & 8,26 \\
\hline 5 & HORUS & 7,04 & 5 & FUCAP & 6,71 \\
\hline 6 & FACVEST & 3,89 & 6 & CATÓLICA & 6,35 \\
\hline 7 & FAl & 3,46 & 7 & UNIBAN & 5,58 \\
\hline 8 & FACULDADE SINERGIA & 1,06 & 8 & FAED & 4,23 \\
\hline 9 & UDESC & $-2,19$ & 9 & FURB & 3,38 \\
\hline 10 & INESA & $-4,17$ & 10 & UNC & 3,36 \\
\hline 11 & UNIBAN & $-4,33$ & 11 & IFES & 2,46 \\
\hline 12 & FAPAG & $-8,21$ & 12 & UNISUL & 1,35 \\
\hline 13 & UNOESC & $-9,79$ & 13 & AVANTIS & $-1,78$ \\
\hline 14 & FAE & $-9,95$ & 14 & IES & $-2,52$ \\
\hline 15 & ESTÁCIO DE SÁ & $-10,94$ & 15 & UNIBAVE & $-2,97$ \\
\hline 16 & FEAN & $-10,94$ & 16 & UNOESC & $-4,84$ \\
\hline 17 & UNIVILLE & $-11,12$ & 17 & FASC & $-5,43$ \\
\hline 18 & UNC & $-11,80$ & 18 & UNIPLAC & $-7,26$ \\
\hline 19 & FAED & $-11,97$ & 19 & FAl & $-7,55$ \\
\hline 20 & ESUCRI & $-14,08$ & 20 & UDESC & $-7,92$ \\
\hline 21 & UNESC & $-14,48$ & 21 & BARDDAL & $-8,27$ \\
\hline 22 & CATÓLICA & $-14,80$ & 22 & FAMEBLU & $-9,70$ \\
\hline 23 & FCSF & $-15,17$ & 23 & USJ & $-10,56$ \\
\hline 24 & FURB & $-16,20$ & 24 & IFES & $-11,37$ \\
\hline 25 & UNIVALI & $-17,29$ & 25 & UNISOCIESC & $-11,55$ \\
\hline 26 & IFES & $-17,43$ & 26 & UNIVALI & $-13,57$ \\
\hline 27 & AVANTIS & $-18,36$ & 27 & FAMEG & $-13,62$ \\
\hline 28 & UNISOCIESC & $-19,37$ & 28 & IBES & $-14,13$ \\
\hline 29 & UNIBAVE & $-19,50$ & 29 & UNIVILLE & $-14,54$ \\
\hline 30 & UNOCHAPECÓ & $-20,59$ & 30 & ESUCRI & $-14,87$ \\
\hline 31 & FAMESUL & $-21,63$ & 31 & UNIASSELVI & $-15,31$ \\
\hline 32 & UNIPLAC & $-22,22$ & 32 & UNOCHAPECÓ & $-15,33$ \\
\hline 33 & IFES & $-22,79$ & 33 & FLC & $-15,64$ \\
\hline 34 & FLC & $-23,88$ & 34 & UNIFEBE & $-17,12$ \\
\hline 35 & FAMEBLU & $-24,14$ & 35 & BORGES MENDONÇA & $-20,55$ \\
\hline 36 & UNISUL & $-24,44$ & 36 & UNIDAVI & $-24,44$ \\
\hline 37 & SOCIESC & $-24,55$ & 37 & FEAN & $-25,32$ \\
\hline 38 & IES & $-25,44$ & 38 & FAEM & $-26,40$ \\
\hline 39 & FAP & $-25,48$ & 39 & SOCIESC & $-27,06$ \\
\hline 40 & UNIFEBE & $-25,52$ & 40 & UNIARP & $-27,84$ \\
\hline 41 & FAMEG & $-27,05$ & & & \\
\hline 42 & FACULDADE DECISÃO & $-28,21$ & & & \\
\hline 43 & UNIDAVI & $-29,55$ & & & \\
\hline 44 & IBES & $-36,79$ & & & \\
\hline 45 & FACC & $-36,91$ & & & \\
\hline 46 & BORGES MENDONÇA & $-36,97$ & & & \\
\hline 47 & UNIARP & $-39,88$ & & & \\
\hline
\end{tabular}

Fonte: Dados da pesquisa. 
Destaca-se que, na amostra total, o número de instituições com curso de Administração (47) é maior do que o número de IES com curso de Ciências Contábeis (40). Além do que, há instituições que possuem curso de Administração, porém não dispõem do curso de Ciências Contábeis e vice-versa; outras já se repetem contendo ambos os cursos.

É possível observar no ranking que as IES do curso de Administração que possuem menor evasão acadêmica são Faculdade Cenecista de Joinville (FACE), Faculdade Municipal de Plalhoça (FMPSC) e UFSC, e as instituições que possuem o maior número de evasão são Faculdade de Concórdia (FACC), Borges Mendonça e UNIARP. Em relação às IES do curso de Ciências Contábeis, as instituições que apresentam menor evasão acadêmica são Universidade do Extremo Sul Catarinense (UNESC), UFSC e FACVEST, e as IES que apresentam o maior número de evasão são Faculdade Empresarial de Chapecó (FAEM), SOCIESC e UNIARP.

A média das instituições do curso de Administração no ranking está para-14,99. Ao estabelecer um corte que limite os posicionamentos, com o intuito de melhor identificar e discutir o ranking das respectivas IES quanto à evasão nesse curso, determinaram-se os valores entre -29,74 e-0,24, ou seja, as instituições que estiverem dentro desta limitação (valores mínimos e máximos determinados a partir da média e +/- 1 desvio-padrão) são as IES que possuem valores de evasão considerados coerentes e que naturalmente uma instituição pode vivenciar. Já a parcela que está fora deste intervalo merece maior atenção. Assim, as IES que estiverem abaixo do limite merecem atenção por estarem com sua evasão elevada, como é o caso do Instituto Blumenauense de Ensino Superior (IBES), FACC, Borges Mendonça e UNIARP, assim como as instituições que estão fora desta margem, apresentando valores acima do corte (Faculdade Cenecista de Joinville (FACE), FMPSC, UFSC, ANHANGUERA, HORUS, FACVEST, Faculdade de Itapiranga (FAI) e Faculdade Sinergia), as quais merecem também discussão, por apresentarem pouca saída de estudantes.

Quanto às instituições do curso de Ciências Contábeis, a média no ranking está para -7,48. O corte que limita os posicionamentos para uma melhor identificação do ranking das respectivas IES quanto à evasão no referido curso possui valores entre-18,92 (valor mínimo) e 3,97 (valor máximo), construídos da mesma maneira que para o curso de Administração. Portanto a análise será direcionada à parcela que estiver fora desse intervalo, já que sua evasão está elevada (como é o caso da Borges Mendonça, UNIDAVI, Faculdade Energia de Administração e Negócios (FEAN), Faculdade Empresarial de Chapecó (FAEM), SOCIESC e UNIARP), bem como as instituições que estão fora deste limite representando valores acima do corte (UNESC, UFSC, FACVEST, ANHANGUERA, Faculdade Capivari (FUCAP), CATÓLICA, Faculdade União Bandeirante (UNIBAN) e Faculdade Educacional de Dois Vizinhos (FAED), as quais merecem também discussão, por apresentarem uma saída reduzida de estudantes.

Os resultados relativos ao alto grau de evasão em ambos cursos coadunam com os apontamentos de Gisi (2006), Troelsen e Laursen (2014) e Wolter, Diem e Messer (2014), pois os fatores socioeconômicos podem estar relacionados à saída acadêmica da instituição, visto que as IES que se figuram com alta evasão em ambos os cursos, a UNIARP e Borges Mendonça, cobram mensalidades de seus acadêmicos. Adicionalmente, a UNIARP se encontra em uma das regiões com menor IDH e baixa renda per capita também, se comparada às demais regiões do estado. Conforme destacam Troelsen e Laursen (2014), as demandas de primeira necessidade tornam-se mais relevantes do que a formação em ensino superior, haja vista que a maioria pertence às classes sociais menos favorecidas. Portanto é possível apontar a falta de recursos financeiros 
do aluno como uma das causas proeminentes para a interrupção de seus estudos. Tal situação recorrentemente acontece com estudantes de classe social menos favorecida e que possuem limitações para seu ingresso em uma IES pública (ausência da aquisição de capital cultural), na qual poderiam se beneficiar de recursos financeiros para seus estudos (GISI, 2006; WOLTER; DIEM; MESSER, 2014).

Outro motivo apontado na literatura é em razão de que os estudantes das referidas áreas, em sua grande maioria, exercem atividades profissionais concomitantes com os estudos, principalmente os estudantes das IES privadas, para viabilizarem financeiramente seus estudos (BRAGA; PEIXOTO; BOGUTCHI, 2003). Além da situação socioeconômica da região em que a IES está inserida, outro elemento a se destacar é o fato de que a maioria dessas IES são caracterizadas como privadas, portanto a própria disponibilização de bolsas de estudo pode ser outro mecanismo que impossibilite a permanência dos estudantes.

Os achados relativos às instituições de ensino que possuem pouco grau de evasão vão ao encontro dos argumentos supracitados. As IES privadas que se encontram nessa condição atuam em regiões do estado com melhores condições socioeconômicas. Nas IES públicas, a exemplo da UFSC, o que se repete em ambos os cursos, tratando-se de uma unidade de ensino pública e localizada em uma região desenvolvida economicamente, os estudantes acabam por se manterem pelos recursos da IES que estão disponíveis a eles, proporcionando condições de permanência na IES. Esse achado corrobora com os trabalhos de Cunha et al. (2015) e Cunha, Nascimento e Oliveira Durso (2016), quando destacam que as menores taxas de evasão dos referidos cursos estão nas instituições públicas.

Também, é preciso destacar que há o papel da IES ao realizar seus trabalhos em relação à permanência do estudante. A atenção dos gestores deve ser intensificada nos primeiros semestres, para que pelo menos se evite a evasão acadêmica da instituição, se não puder ser evitada no curso. No caso das IES privadas localizadas em regiões com baixo poder aquisitivo, a possibilidade de financiamentos e/ou aumento de liberação de bolsas de estudos por meio de parcerias com a inciativa privada pode representar uma alternativa para que se possa reduzir a taxa de desistência dos alunos nos cursos de Administração e Ciências Contábeis.

\section{CONSIDERAÇÕES FINAIS}

Este artigo teve como propósito identificar e discutir a evasão acadêmica dos cursos de Administração e Ciências Contábeis nas instituições de ensino superior de Santa Catarina. Para isso, utilizou-se o método CRITIC para a análise dos dados e ranqueamento das instituições quanto à evasão acadêmica no período de 2010 a 2014.

Em suma, com os resultados obtidos neste trabalho, pôde-se apontar que: (a) os cursos de Administração e Ciências Contábeis, nas IES em análise, apresentam, sim, elevado número de evasão acadêmica; (b) a taxa de desistência acumulada é a que apresenta maior variação entre as IES e em ambos os cursos; (c) o curso de Administração tem mais evasão acadêmica se comparado ao de Ciências Contábeis; (d) as IES privadas localizadas em regiões com menor IDH e baixa renda per capita possuem maior taxa de evasão se comparadas às IES públicas e privadas localizadas em regiões mais desenvolvidas.

Argumenta-se que tais resultados se devem principalmente: (a) ao fato da grande maioria dos estudantes dos cursos de Administração e Ciências Contábeis exercerem atividades pro- 
fissionais concomitantes com os estudos, principalmente nas IES privadas, para viabilizarem financeiramente sua formação acadêmica; (b) as demandas de subsistência se tornam mais relevantes do que a formação em ensino superior, haja vista que grande parte dos estudantes acadêmicos pertence às classes sociais de menor poder aquisitivo. Assim, tal situação é recorrente com estudantes pertencentes a essa classe econômica social e que possuem limitações para seu ingresso em uma IES pública (ausência da aquisição de capital cultural), na qual poderiam usufruir de recursos financeiros para seus estudos na graduação.

Este estudo é baseado e amplia a literatura existente em três perspectivas principais: (i) teórica, por representar um passo na tentativa de integrar abordagens e metodologias quantitativas nos estudos das IES, de forma inédita, considerando e evidenciando a factibilidade da adoção do modelo CRITIC e por considerar os fatores exógenos e relacionados às características das IES; (ii) governamental, chama-se atenção para as políticas públicas de apoio às IES fundacionais do estado, visto que algumas IES com maior evasão representam essa categoria; e (iii) gerencial, uma vez que se fornecem subsídios aos gestores das IES para fazerem benchmarking com as demais IES, de forma a avaliarem as estratégias adotadas e eficiência dos recursos empregados. Portanto o método CRITIC pode ser utilizado para selecionar, dentro de um conjunto de dados, aqueles mais relevantes, e, quiçá, capazes de fazer a diferença em muitas decisões a serem tomadas pelos usuários.

O estudo apresenta limitações que, apesar dos esforços para minimizá-las, ainda persistem. O período de análise selecionado (2010 a 2014) é a primeira limitação a ser destacada; diante disso, deve-se ter a devida cautela com interpretação fora desta série. A amostra intencional não permite que generalizações dos resultados sejam estendidas a outros estados e outros cursos, por exemplo. Espera-se que, em estudos futuros, essas questões possam ser endereçadas, incluindo na análise outros estados, seguindo os mesmos critérios adotados neste trabalho, inclusive que possam considerar na análise a possibilidade de ampliação do corte temporal, à medida que os dados sejam disponibilizados pelo sistema INEP. Uma análise conjunta dos motivos exógenos com os motivos endógenos que estão levando a essa classificação negativa das instituições pode representar também uma promissora perspectiva a ser analisada em pesquisas futuras.

\section{REFERÊNCIAS}

BAGGI, C. A. S.; LOPES, D. A. Evasão e avaliação institucional no ensino superior: uma discussão bibliográfica. Avaliação: Revista da Avaliação da Educação Superior, São Paulo, v. 16, n. 2, p. 355-74, 2011.

BENTES, S. R.; MENEZES, R.; MENDES, D. A. Entropic measures in nonlinear dynamics. In: SALGUEIRO, M. F.; MENDES, D. A.; MARTINS, L. F. (Ed.). Temas em métodos quantitativos. Lisboa: Edições Sílabo, 2009.

BRAGA, M. M.; PEIXOTO, M. C. L.; BOGUTCHI, T. F. A evasão no ensino superior brasileiro: o caso da UFMG. Avaliação: Revista da Avaliação da Educação Superior, Sorocaba, v. 8, n. 3, p. 161-89, 2003.

CUNHA, J. V. A.; LUCA, M. M. M.; LIMA, G. A. S. F.; CORNACCHIONE JR, E. B.; OTT, E. Quem está ficando para trás? Uma década de evasão nos cursos brasileiros de graduação em Administração de Empresas e Ciências Contábeis. Revista de Educação e Pesquisa em Contabilidade (REPeC), Brasília, v. 9, n. 2, p. 124-42, 2015.

CUNHA, J. V. A.; NASCIMENTO, E. M.; OLIVEIRA DURSO, S. Razões e influências para a evasão universitária: um estudo com estudantes ingressantes nos cursos de Ciências Contábeis de instituições públicas federais da Região Sudeste. Advances in Scientific and Applied Accounting, São Paulo, v. 9, n. 2, p. 141-61, 2016. 
DIAKOULAKI, D.; MAVROTAS, G.; PAPAYANNAKIS, L. Determining objective weights in multiple criteria problems: the critic method. Computers \& Operations Research, Amsterdã, v. 22, n. 7, p. 763-70, 1995.

GAMBIRAGE, C.; BOHN, A. C.; HEIN, N.; SILVA, J.; DOMINGUES, M. J. C. S. Elementos de satisfação dos estudantes de cursos de pós-graduação lato sensu em uma instituição do sistema ACAFE no meio-oeste catarinense. Revista Meta Avaliação, Rio de Janeiro, v. 9, n. 27, p. 433-63, 2017 a.

GAMBIRAGE, C.; XAVIER, W. G.; SILVA, J.; GREENE, F.; GANDONOU, J. M. Economic performance of private higher education institutions in distance education through mergers and acquisitions. Revista Eletrônica de Estratégia \& Negócios, Florianópolis, v. 10, n. 1, p. 252-84, 2017b.

GATI, I.; SAKA, N. High school students' career-related decision-making difficulties. Journal of Counseling \& Development, Weinheim, v. 79, n. 3, p. 331-40, 2001.

GISI, M. L. A Educação Superior no Brasil e o caráter de desigualdade do acesso e da permanência. Revista Diálogo Educacional, Curitiba, v. 6, n. 17, p. 97-112, 2006.

INSTITUTO NACIONAL DE ESTUDOS E PESQUISAS EDUCACIONAIS ANÍSIO TEIXEIRA [INEP]. Censo da Educação Superior. INEP, Brasília-DF, 2017. Disponível em: https://inep.gov.br/censo-da-educacaosuperior. Acesso em: 30 dez. 2019.

LAS CASAS, A. L.; GUEVARA, A. J. H.; MERIGHI, C. C. Avaliação de serviços em Instituições de Ensino Superior para o Desenvolvimento Local. Interações, Campo Grande, v. 14, p. 11-24, 2013.

LEAL, E. A.; MIRANDA, G. J.; CARMO, C. R. S. Teoria da autodeterminação: uma análise da motivação dos estudantes do curso de ciências contábeis. Revista Contabilidade \& Finanças, São Paulo, v. 24, n. 62, p. 162-73, 2013.

LUNA, I. N.; BARDAGI, M. P.; GAIKOSKI, M. M.; MELO, F. D. S. Empresas juniores como espaço de desenvolvimento de carreira na graduação: reflexões a partir de uma experiência de estágio. Revista Psicologia Organizações e Trabalho, Florianópolis, v. 14, n. 4, p. 441-51, 2014.

NJOKU, J. C.; HEIJDEN, B. I. V. D.; INANGA, E. L. Fusion of expertise among accounting faculty: towards an expertise model for academia in accounting. Critical Perspectives on Accounting, Amsterdã, v. 21, n. 1, p. 51-62, 2010.

OLIVEIRA, R. T. D.; BARBOSA, E. D. Retenção dos discentes de Administração da UFS: fatores condicionantes e ações da gestão acadêmica. Administração: Ensino e Pesquisa, Rio de Janeiro, v. 17, n. 2, p. 355-80, 2016.

OSBORNE, J. W.; JONES, B. D. Identification with academics and motivation to achieve in school: how the structure of the self influences academic outcomes. Educational Psychology Review, Berlim, v. 23, n. 1, p. 131-58, 2011.

PIERRE, K. S. T.; WILSON, R. M. S.; RAVENSCROFT, S. P.; REBELE, J. E. The role of accounting education research in our discipline: an editorial. Issues in Accounting Education, Atlanta, v. 24, n. 2, p. 112-130, 2009.

RAMOS, F. M.; NEZ, E. D.; HEIN, N. Ranking das instituições de Ensino Superior do Sistema ACAFE a partir dos indicadores de desempenho econômico, financeiro e de atividades. Pensar Contábil, Rio de Janeiro, v. 16, n. 30, p. 52-60, 2014.

SILVA, A. M.; SAUAIA, A. C. A. Evasão e qualidade em instituições de Ensino Superior privadas: uma análise da economia dos custos de transação. Administração: Ensino e Pesquisa, Rio de Janeiro, v. 15, n. 4, p. 805-30, 2014 
SILVA FILHO, R. L. L.; MOTEJUNAS, P. R.; HIPÓLITO, O.; LOBO, M. B. C. M. A evasão no ensino superior brasileiro. Cadernos de pesquisa, Maranhão, v. 37, n. 132, p. 641-59, 2007.

TROELSEN, R.; LAURSEN, P. F. Is drop-out from university dependent on national culture and policy? The Case of Denmark. European Journal of Education, Weinheim, v. 49, n. 4, p. 484-96, 2014.

WOLTER, S. C.; DIEM, A.; MESSER, D. Drop-outs from swiss universities: an empirical analysis of data on all students between 1975 and 2008. European Journal of Education, Weinheim, v. 49, n. 4, p. 471-83, 2014.

\section{Sobre os autores:}

Cinara Gambirage: Doutoranda em Ciências Contábeis e Administração pela Universidade Regional de Blumenau (FURB). Mestre em Administração pela Universidade do Sul de Santa Catarina (UNISUL). Especialista em Docência na Educação a Distância pela Faculdade de Administração e Economia (FAE). Graduada em Letras trilíngue pela Universidade Alto Vale do Rio do Peixe (UNIARP). Graduanda em Administração pela UNIARP. Atualmente, é docente nos cursos de graduação na UNIARP, de Caçador, Santa Catarina. E-mail: naraboniii_@hotmail.com, Orcid: https://orcid.org/0000-0002-8166-1171

Jaison Caetano da Silva: Doutorando em Administração pela Universidade do Vale do Itajaí (UNIVALI). Mestre em Administração pela Universidade do Sul de Santa Catarina (UNISUL). Especialista em Gestão Estratégica de Finanças, Contabilidade e Controladoria pela Universidade Alto Vale do Rio do Peixe (UNIARP). Graduado em Matemática e em Administração pela UNIARP. E-mail: jaisoncsilva@hotmail.com, Orcid: https://orcid.org/0000-0001-8516-5821

Nelson Hein: Pós-doutor pela Associação Instituto Nacional de Matemática Pura e Aplicada (IMPA) e pela Universidade do Novo México, Estados Unidos. Doutor e mestre em Engenharia de Produção pela Universidade Federal de Santa Catarina (UFSC). Especialista em Ensino de Ciências/ Matemática pela Fundação Universidade Regional de Blumenau (FURB). Graduado em Ciências e em Matemática pela FURB. Professor do Departamento de Matemática; e no Programa de PósGraduação em Ciências Contábeis (PPGCC) na FURB. Coordena o grupo de Estudos MULTIVAR. E-mail: nhein@furb.br, Orcid: https://orcid.org/0000-0002-8350-9480

Maria José Carvalho de Souza Domingues: Doutora em Engenharia de Produção pela Universidade Federal de Santa Catarina (UFSC). Mestre e graduada em Administração pela UFSC. É professora titular da Universidade Regional de Blumenau (FURB), no Departamento de Administração. Nos Programas de Pós-Graduação em Administração e de Ciências Contábeis, ministra disciplinas e desenvolve pesquisas relacionadas à gestão universitária e a tecnologias no ensino. E-mail: mjdomingues@furb.br, Orcid: https://orcid.org/0000-0001-7771-144X

Adriana Kroenke: Doutora pelo Programa de Métodos Numéricos e Engenharia da Universidade Federal do Paraná (UFPR). Mestre em Ciências Contábeis pela Universidade Regional de Blumenau (FURB). Graduada em Matemática pela Universidade Regional de Blumenau (FURB). Professora do Departamento de Matemática na FURB. Atualmente, é professora permanente do Programa de Pós-Graduação em Administração e do Programa de Pós-Graduação em Ciências Contábeis na FURB. Integrante do grupo de estudos MULTIVAR. E-mail: kroenke@furb.br, Orcid: http://orcid.org/0000-0001-6625-3017 